\title{
MENGAPA TEROR HARUS ABADI?
}

Oleh Shohibul Anshor Siregar

\section{Bagian 1}

Saya ingin memulai pembahasan dengan memaparkan kejadian-kejadian berkategori teror yang pernah dicatat oleh sejarah. Untuk pekerjaan seperti ini kita tak boleh tunduk pada sumber tunggal, karena apa yang disebut teror oleh kalangan tertentu akan selalu dipandang lain oleh penganut perspektif atau pandangan politik yang berbeda.

Terrorism is characterized not only by its manifold nature and complexity but also by the problem with its definition What is terrorism then? How can one define it? Which of the several hundreds of definitions is accurate? Why are they so numerous? The above questions only appear to be easy, or even trivial. They have actually been troublesome, even to those who have been analyzing and researching these problems for years.

Hegemoni internasional ternyata begitu dominan untuk penentuan teror dan apa yang disebut teror selama ini. Begitulah, bahwa stelah kejadian 911 arah yang begitu jelas memusuhi Islam dalam kebijakan menghadapi teror ${ }^{2}$ :

The September 11 attacks on the US dramatized the relationship between media spectacles of terror and the strategy of Islamic Jihadism that employs violent media events to promote its agenda. But US administrations have also used spectacles of terror to promote US military power and geopolitical ends, as is evident in the Gulf war of 1990-1991, the Afghanistan war of fall 2001, and the Iraq war of 2003.

Saat ini bahkan cukup populer pemahaman di seluruh dunia bahwa "tidak semua muslim teroris, tetapi semua teroris adalah muslim" 3 . Statemen itu adalah bagian dari bahasa dan publikasi dunia yang secara hegemonik mendegradasi komunitas dan Negara muslim yang diposisikan secara peyoratif.

Teror selalu berakar pada ketidakadilan. Jika ketidakadilan itu sudah melekat pada struktur kehidupan sosial umat manusia, maka teror adalah warisan yang menjadi fungsi ketakadilan itu sendiri tanpa melihat kelompok dan agama korban dan pelaku ${ }^{4}$.

Dalam kajian James Scott ${ }^{5}$ dijelaskan bahwa konflik kekerasan asimetris tidak selalu diharapkan berlangsung fair sesuai ketidakadilan yang melandasinya. Perlawanan tak terduga seperti ini dapat disaksikan dalam ribuan perlawanan di semua bangsa-bangsa jajahan. Jiih dan Pitung dari Tanah Betawi adalah sama-sama teroris, ekstrimis, intoleran bagi Belanda, sebagaimana Naga Bonar yang begitu identik dipojokkan seperti orang yang sekarang ini memberi perlawanan ide kepada pemerintah ${ }^{6}$.

Dalam sejarah penanganan teror belakangan tak banyak negara yang tak tunduk ada sebuah agenda mendunia war on terrorism yang dikendalikan Amerika sejak 
pemerintahan Bush. Karena itulah kerangka pemikiran mau pun solusi teror selalu tak mengakar pada masalah internal suatu negara, bahkan kebanyakan menjadi agenda pesanan adidaya. Hal ini tak terkecuali dengan Indonesia yang lucunya sebagai negara mayoritas berpenduduk muslim justru muslimnya yang dituduh teroris. Ini aneh?

MC Bassiouni (Emeritus Professor of Law dari DePaul University 1964-2012) menegaskan bahwa untuk mendefinisikan terorisme yang tak ambigu dan memuaskan setiap orang, adalah sebuah ketak-mungkinan. Hal itu disebabkan oleh perbedaan fundamental values yang berbenturan antara satu dan lain orang, antara satu dan lain bangsa, dan antara satu agama dengan lain dalam menilai tindakan kekerasan itu ${ }^{8}$.

Bahwa semua yang disebut terorisme itu adalah perang non-official dan jika dibandingkan dengan banyak perang yang tercatat dalam sejarah, sangat tidak bermakna baik dilihat dari aspek korban maupun akibatnya bagi kehidupan manusia. Memang agak sinis, tetapi Professor Johnson (Rutgers University) sangat tepat menyebut terorisme itu just another war ${ }^{9}$. Mari kita telaah lebih mendalam.

\section{Bagian II}

\section{Teror dan berbagai kepentingannya}

Pada abad XIX susah mendapatkan data yang mengaitkan komunitas muslim dengan tindakan teroris. Pada tahun 1881 Tsar Alexander II dicederai dalam sebuah peledakan bom yang menewaskan 21 orang. Belakangan diketahui bahwa pelakunya adalah Ignacy Hryniewiecki, bukan seorang muslim ${ }^{10}$. Pada tahun 1886, saat konflik perburuhan, sebuah bom meledak di Haymarket Square, Chicago menewaskan 20 orang $^{11}$.

Bagaimana pada abad XX? Tanggal 6 September 1901 Presiden AS William McKinley ${ }^{12}$ menjadi korban pembunuhan pada Pameran Pan-Amerika di Buffalo, New York. Seorang anarkis (28 tahun), Leon Czolgosz, adalah pelakunya. la, bukan seorang muslim. Tanggal 1 Oktober 1910 ledakan bom di gedung surat kabar Time, Los Angeles membunuh 21 orang. Pelakunya dua orang beragama Kristen, James dan Joseph ${ }^{13}$.

Tanggal 28 Juni 1914 Archduke of Austria dan isterinya tewas dalam pembunuhan di ibukota provinsi Austro-Hungaria dari Bosnia dan Herzegovina, oleh Gavrilo Princip, berusia 19 tahun. Anak muda ini adalah anggota Young Bosnia, bukan seorang muslim ${ }^{14}$. Tanggal 19 April 1925 terjadi ledakan bom di gereja St.Negelya, Sofia, ibukota Bulgaria, yang menewaskan ratusan orang. Pelakunya ialah partai komunis dan tak satu pun di antara pelakunya beragama Islam ${ }^{15}$. Tanggal 9 Oktober 1934 King 
Alexander I Yugoslavia terbunuh dengan sebuah tembakan oleh Vlada Georgieff, bukan seorang muslim ${ }^{16}$.

Pada tanggal 1 Mei 1961 pesawat milik Amerika Serikat dibajak. Pelakunya ialah Ramirez Ortiz, bukan muslim ${ }^{17}$. Seorang non muslim pada tanggal 28 Agustus 1968 juga tercatat membunuh Duta Besar Amerika Serikat untuk Guatemala ${ }^{18}$. Pada tanggal 30 Juli 1969 Duta besar Amerika Srikat untuk Jepang juga terbunuh dengan bersenjatakan sebilah pisau, oleh seorang berkewarganegaraan Jepang, non muslim ${ }^{19}$. Tanggal 3 September 1969, Duta Besar Amerika Serikat untuk Brazil diculik. Bukan oleh seorang muslim ${ }^{20}$. Tanggal 19 April 1995 Gedung Federal di Oklahoma dibom dengan menggunakan sebuah truk yang menyebabkan tewasnya ratusan orang. Pelakunya Timothy dan Terry, anggota gerakan sayap kanan. Bukan muslim²1.

Rentang waktu antara 1941 hingga 1948 usai perang dunia II, 259 kali serangan brutal dilakukan oleh teroris Jahudi22. Pada tanggal 22 Juli 1946 bom yang meledak di Hotel King David (Jerusalem) dilakukan oleh geng teroris bernama Irgun bekerja sama dengan geng Stern yang dikenal memiliki hubungan manajemen khusus di bawah arahan Managem Begin, dengan korban 91 orang termasuk tokoh Desir Yassin. Dikhabarkan bahwa mantan Perdana Menteri Shamir juga pernah menjadi anggota Irgun dan kemudian pindah ke Stern yang dikenal memang lebih radikal. Tetapi bom itu diasosiasikan dengan pekerjaan muslim. Dua tahun kemudian, dia menjadi Perdana Menteri Israel. la juga kemudian menjadi penerima hadiah Nobel perdamaian. Bayangkanlah itu. Sebelum 1945 Israil tidak akan ditemukan dalam peta. Para teroris itulah yang membangunnya ${ }^{23}$.

Di Jerman antara tahun 1968 sampai 1992, geng bernama Baader Meinhoff membunuh sejumlah orang tak berdosa ${ }^{24}$. Brigade Merah di Italia melakukan pembunuhan-pembunuhan atas sejumlah orang tak berdosa, juga menculik dan setelah 5 hari kemudian membunuh Aldo Moro, mantan perdana menteri Italia ${ }^{25}$. Tanggal 20 Maret 1995 Aum Shinrikyo, sebuah sekte Budha dari Jepang, menimbulkan kehebohan berskala internasional, ketika beberapa anggotanya melaksanakan serangan gas sarin di kereta bawah tanah Tokyo. Teror ini menewaskan 12 orang, 54 orang sakit parah, serta memengaruhi lebih dari 980 orang $^{26}$.

Di Inggeris tentara separatis Irish Republican Army (IRA) selama ratusan tahun melakukan kekerasan-kekerasan dengan korban yang besar. Mereka beragama Katholik dengan perjuangan yang ideologis. Tahun 1991 IRA juga membom kantor $B C^{27}$. Di Spanyol dan Perancis, Euskadi Ta Askatasuna (ETA), sebuah kelompok gerakan separatis bersenjata tercatat melakukan ratusan kali terror dengan jumlah korban yang juga begitu besar, sejak tahun 1961 hingga 201128. The Lord's Resistance Army (LRA), yang juga dikenal dengan nama Lord's Resistance Movement, adalah sebuah kelompok pemberontak sekte heterodox Christian yang beroperasi di Uganda 
bagian Utara, Sudan Selatan dan Republik Afrika Tengah dan Republik Demokratik Kongo. Mereka melatih anak-anak untuk melakukan teror. Tetapi begitulah dunia tidak menyebutnya sebagai apa adanya ${ }^{29}$.

Di Sri Langka ada Liberation Tigers of Tamil Eelam (LTTE) atau yang di Indonesia lebih dikenal dengan nama Macan Tamil. la adalah suatu gerakan insurgensi yang berbasiskan etnis, bertujuan mendirikan Negara Tamil yang independen di Tenggara Sri Lanka ${ }^{30}$.

Sejak dibentuk pada tahun 1976 oleh Velupillai Prabhakharan telah melancarkan gerakan-gerakan gerilya melawan pemerintah Sri Lanka. Gerakan teror ini lebih terkenal karena divisi bom bunuh dirinya bernama Macan Hitam yang dibentuk pada tahun 1987 dan telah melancarkan ratusan aksi bom bunuh diri (termasuk pembunuhan Perdana Menteri India, Rajiv Gandhi). Mereka Hindu ${ }^{31}$.

Di India boleh dikatakan hampir semua kelompok agama termasuk kelompok komunis memiliki organisasi teroris dengan catatan-catatan kekerasan menewaskan banyak nyawa tak berdosa. Media tak tertarik menelisiknya sebagai teror berdasarka ideologi dan agama. Ketika muncul sebagai newsbrief di halaman media, sangat berbeda jika ada kejadian kekerasan ketika di mana-mana dikaitkan dengan muslim ${ }^{32}$.

\section{Catatan Tentang "Rezim Pembunuh"}

Siapakah manusia paling bengis di dunia sepanjang sejarah yang pernah membunuh banyak orang? Sebutlah Hitler yang membunuh 6 juta Jahudi. Itu belum termasuk korban pada perang dunia kedua lainnya. Siapa dia? Dia orang Kristen ${ }^{33}$.

Joseph Stalin adalah salah satu dari tujuh anggota pertama Politbiro, yang didirikan pada tahun 1917 untuk mengelola Revolusi Bolshevik, bersama Lenin, Zinoviev, Kamenev, Trotsky, Sokolnikov dan Bubnov. Tokoh besar komunis ini menewaskan antara 20 sampai 60 juta jiwa dalam sejarah Rusia ${ }^{34}$.

Di China, Mao Tse Tung tercatat menewaskan paling sedikit 14 juta jiwa. la non muslim ${ }^{35}$. Benito Musollini menewaskan 400 ribu jiwa ${ }^{36}$. la bukan muslim. Selama revolusi Francis Maximilin Robespierre bertanggung jawab atas tewasnya 200.000 jiwa ${ }^{37}$. Ashoka dalam salah satu pertempuran Kalingga tercatat membunuh 100.000 jiwa. Dia orang Hindu ${ }^{38}$.

Saddam Husein menewaskan 100.000 ribu jiwa, namun itu semua harus dikaitkan dengan embargo Barat dan Geroge Bush yang membunuh lebih dari setengah juta anak-anak di Irak ${ }^{39}$. Banyak orang mengklaim tewasnya 500.000 orang era Soeharto ${ }^{40}$, tetapi ini tak mungkin dibandingkan dengan Stalin, Hitler dan Mao. 
Soeharto bukan muslim fundamentalis, ekstrimis atau teroris. Itu tak mungkit dikaitkan dengan Islam.

\section{Mitologi dan perang}

Mitologi Afrika mengenal 6 dewa perang, Mesir 14, Cina 6 (utama) dan ratusan dewa perang lainnya, Greek 25, Roma 9 perang, Hindu 30, Jepang 8, dan Semitik 7. Apakah ada pengaruh dari mitologi itu terhadap bentuk-bentuk kekerasan yang pernah terjadi sepanjang sejarah umat manusia? Saya kira mustahil tak ada benang merahnya. Selain itu, mencurigai doktrin agama secara adil, khususnya agama yang dibawa oleh penjajahan Eropa, agaknya susah menyebut perang-perang lebih besar yang hadir atas nama hegemoni dalam sejarah kecuali yang sungguh-sungguh terkait dengan gosple, glory dan gold ${ }^{41}$.

- Antara 3 sampai 15 juta tercatat tewas karena Thirty Years' War yang dilaksanakan atasnama Holy Roman Empire (1618-1648), dan itu perang atas nama agama (Katholik vs Protestan). Jumlah korban itu mencapai $0.5 \%-2.1 \%$ dari penduduk dunia saat itu ${ }^{42}$.

- Antara 2 hingga 4 juta (0.4\%-0.8\% dari penduduk dunia saat itu) telah tewas dalam perang agama antara Katholik dan Protestan di Perancis (1562-1598) 43.

- Serbuan Kristen terhadap Islam dalam perang Salib menewaskan 1 hingga 3 juta jiwa (1095-1291) yang kurang lebih setara dengan 0.3\%-2.3\% dari penduduk dunia saat itu ${ }^{44}$.

- Antara 1 hingga 2 juta tewas dalam Perang Sipil Sudan II (1983-2005). Ini perang agama antara Kristen ${ }^{45}$.

- Catatan sejarah dunia juga menyebut antara 130 ribu hingga 250 ribu tewas dalam perang Sipil Libanon yang terjadi antara tahun 1975 hingga 1990. Sunni, Syiah, Jahudi, Druze dan Kristen terlibat di dalamnya ${ }^{46}$.

- Perserikatan Bangsa-Bangsa memperkirakan setidaknya sudah 1.000 orang yang tewas dalam operasi "balasan" yang disebut dengan "pembersihan etnis" di Myanmar dan pada saat yang sama 400 ribu orang lainnya terpaksa mengungsi ke Bangladesh dan tinggal dalam kondisi seadanya ${ }^{47}$.

\section{Bagian III}

Amat perlu mengenali pola insiden teror yang pernah terjadi di Indonesia. Data untuk itu kini cukup mudah untuk diakses dari berbagai sumber.

Beberapa ledakan bom yang terjadi di Indonesia sejak tahun 2000 dinyatakan cukup mengguncang dan menjadi perhatian dunia. Pertama, Bom Bursa Efek Jakarta yang trejadi tanggal 13 September 2000 persis satu hari sebelum pembukaan Olimpiade 
Musim Panas. Kedua, Bom Bali I tanggal 12 Oktober 2002 yang memantik reaksi keras dari banyak negara. Tiga tempat berbeda di Bali menjadi sasaran, yaitu Paddy's Club, Sari Club (SC) di Jalan Legian, Kuta dan di dekat Kantor Konsulat Amerika Serikat.

Ketiga, Bom JW Marriot tanggal 5 Agustus 2003. Bom bunuh diri ini menewaskan 150 orang. Keempat, Bom Kuningan tanggal 9 September 2004 yang ditujukan kepada Kantor Kedutaan Besar Australia. Selain membuat beberapa orang meninggal, peristiwa ledakan ini juga membuat bangunan di sekitarnya rusak parah.

Kelima, bom Bali II tanggal 1 Oktober 2005 yang menewaskan sedikitnya 23 orang dan melukasi 196 orang lainnya. Ledakan bom bunuh diri ini juga dilakukan di 3 tempat yang berbeda dengan tipe bom yang berbeda pula: 2 tempat di Kuta dan 1 tempat di kawan Jimbaran, Bali. Keenam, bom Mega Kuningan tanggal 17 Juli 2009 yang menewaskan sedikitnya 9 orang dan melukai 50 orang lainnya. Ketujuh, bom Sarinah tanggal 14 Januari 2016 yang terjadi di sekitar Jalan MH Thamrin, Jakarta. Selain ledakan, terjadi pula baku tembak antara para pelaku dan pihak kepolisian. Sedikitnya 7 orang tewas akibat aksi teror bom tersebut. Di antaranya adalah seorang polisi lalu lintas dan seorang warga Belanda.

Meski terasa sangat tidak adil, umumnya Indonesia mencatat sejarah teror sejak zaman Orde Baru. Padahal apa yang dilakukan terhadap para pejuang dan komunitas-komunitas nasionalis yang menentang kekuasaan kolonial yang bahkan berkategori genosida tak dianggap sebagai teror. Namun di bawah ini diberikan catatan yang umumnya sudah diketahui oleh publik ${ }^{48}$, yakni 1957: Teror bom pertama setelah Indonesia merdeka yang dinyatakan bersasaran Presiden Soekarno yang sedang berkunjung ke sekolah Perguruan Cikini, Jakarta Pusat. 1976: Teror bom terjadi di Masjid Nurul Iman di Padang, Sumatera Barat, diledakkan orang tidak dikenal. 1978: Masjid Istiqlal, Jakarta, diteror bom, dan belum diketahui pelaku dan motifnya hingga kini.

Tanggal 4 Oktober 1984: Bank BCA di Pecenongan, Jakarta Pusat, diledakkan. Aksi ini dikaitkan dengan kelompok yang diberinama Petisi 50. 1985: Bus Pemudi Express diledakkan di daerah Banyuwangi, Jawa Timur, dan pada tahun yang sama sejumlah stupa di Candi Borobudur, Jawa Tengah, berantakan dibom. 1986: Brigade Anti Imperialisme dari Jepang beraksi dengan sasaran Wisma Metropolitan dan Hotel Presiden (sekarang Hotel Nikko) yang adalah milik pemerintah yang dibangun dengan pampasan perang dari Jepang.

Tahun 1991: Gerilyawan Fretilin Kay Ralla Xanana Gusmao meledakkan bom di Demak, Jawa Tengah. 1998: Bulan Januari 1998 bom meledak di sebuah rumah susun di daerah Senen, Jakarta. Pada waktu yang tak berjauhan juga terjadi pemboman tempat parkir kendaraan di Atrium Plaza di Jakarta Pusat. 1999: Pusat perbelanjaan Ramayana di Jalan Agus Salim, Jakarta Pusat, diledakkan dengan pelakunya yang 
sama dengan peledakan Atrium Plaza, pusat perbelanjaan Senen, Jakarta Pusat, tahun 1998. Pada tahun yang sama pusat perbelanjaan Plaza Hayam Wuruk di Jakarta Barat, diledakkan.

Tahun 2000: Saat malam Natal sejumlah gereja di Jakarta, Bekasi, Sukabumi, Bandung, Mojokerto, Mataram, Pematang Siantar, Medan, Batam, dan Pekanbaru, diledakkan. 1 Agustus 2000: Bom meledak di kediaman Duta Besar Filipina untuk Indonesia, di Jalan Imam Bonjol, Jakarta Pusat. Juli 2002: Bom meledak di Graha Mall Cijantung, Jakarta, dekat komplek Kopassus TNI AD. 12 Oktober 2002: Bom meledak di Paddy's Cafe dan Sari Club, dua restoran di Jalan Legian, Kuta, Denpasar, Bali. 5 Agusutus 2003: Bom meledak di Hotel JW Marriot, Jakarta. Korban tewas 14, dan luka-luka 156. 10 September 2006: Bom meledak di Kedutaan Besar Australia, Jakarta. Jumlah korban sekitar 6 sampai 9 orang. 1 Oktober 2005: Bom meledak di Kuta Bali yang kemudian lebih dikenal sebagai tragedi Bom Bali II. 17 Juli 2009: Bom meledak di Hotel JW Marriot dan Ritz Carlton.

Bulan April 2015: Permukiman padat penduduk di kawasan Tanah Abang, Jakarta Pusat, dibom. Juli 2015: Bom meledak di Mall Alam Sutera, Tangerang, Banten. 28 Oktober 2015: Bom meledak di Mall Alam Sutera. November 2015: Bom meledak di Jalan Raden Inten, Duren Sawit, Jakarta Timur.

\section{Bagian IV}

Menurut laporan PBB Seventieth session Agenda items 16 and 117 Culture of peace The United Nations Global Counter-Terrorism Strategy Plan of Action to Prevent Violent Extremism, selama dua dekade terakhir masyarakat internasional yang dikendalikan melalui unit negara-negara telah berusaha mengatasi apa yang disebut sebagai violent extremism terutama dalam konteks tindakan anti-terorisme berbasis keamanan. Hal itu tak lain dari upaya yang secara langsung diadopsi sebagai tanggapan atas apa yang dinyatakan sebagai ancaman yang timbul secara ekskalatif oleh kelompok-kelompok yang dinyatakan sebagai kelompok teror ${ }^{49}$.

Dalam resolusi 2178 (2014) kelihatannya Dewan Keamanan telah sedikit berusaha membuat secara eksplisit kaitan antara violent extremism dan terorisme, sembari menekankan sesuatu untuk sekadar menggarisbawahi pentingnya tindakan yang sesuai dengan norma internasional dan mengakui perlunya tindakan pencegahan ${ }^{50}$.

Aneka bentuk dan skala violent extremism, yang dapat menjadi pemicu bagi munculnya situasi kondusif bagi pertumbuhan subur segala bentuk terorisme, nyata benar membutuhkan upaya bersama, termasuk mungkin harus lebih mengutamakan upaya mencegah radikalisasi, rekrutmen dan mobilisasi individu ke dalam berbagai kelompok teror dan menjadi tokoh-tokoh diehard di sana. Menyadari berbagai 
penyimpangan yang terjadi meluas di hampir seluruh Negara, maka dalam resolusi Dewan Keamanan PBB ini diserukan agar Negara-negara anggota secara serius meningkatkan upaya melawan, dengan mengakui bahwa kerja sama internasional dan tindakan yang diambil untuk mencegah dan memberantas terorisme harus sepenuhnya mematuhi Piagam Perserikatan Bangsa-Bangsa ${ }^{51}$.

Majelis Umum PBB memang telah mengambil pendekatan praktis untuk melawan terorisme melalui adopsi konsensus Strategi Penanggulangan Terorisme Global PBB. Tetapi Rencana Aksi yang digariskan justru menerapkan pendekatan amat praktis berdasarkan subjektivisme tertentu yang bisa tak bertepi, untuk alasan mencegah berbagai hal yang dianggap ekstremisme dan kekerasan, tanpa merasa berkewajiban menusahakan untuk menjawab pertanyaan tentang definisi yang benar tentang terorisme itu sendiri.

Dalam resolusi 2178 (2014) memang telah ditegaskan adanya kebutuhan untuk mengambil pendekatan yang lebih komprehensif. Hal ini mestinya mencakup tidak hanya tindakan kontra-terorisme berbasis keamanan yang berkelanjutan, tapi juga prioritas tindakan-tindakan pencegahan sistematis yang secara langsung menangani faktor-faktor luas yang pendorong violent extremism yang telah melahirkan kemunculan bentuk-bentuk kelompok baru yang dapat saja lebih ganas. Tetapi hingga kini resolusi ini tak berdaya atau dibiarkan tak berdaya sama sekali.

Dalam Piagam PBB, Negara-negara anggota sebetulnya telah memutuskan untuk mengambil tindakan kolektif yang efektif untuk pencegahan dan penghapusan ancaman terhadap perdamaian. Prinsip ini sudah benar adanya. Mestinya siapa pun dan Negara mana pun, wajib menjadikannya sebagai prioritas untuk memberi energi kembali pada tindakan-tindakan pencegahan yang rasional, termasuk dalam agenda pencegahan konflik bersenjata, kekejaman, bencana kekerasan terhadap perempuan dan anak-anak, dan kekerasan seksual terkait konflik, dan inisiatif-inisiatif khusus untuk menempatkan hak asasi manusia di atas segalanya.

Ada sejumlah rujukan yang menekankan perlunya membangun komitmen kolektif untuk melakukan pencegahan.

Pertama, Laporan Panel Independent untuk Operasi Perdamaian Perserikatan BangsaBangsa tahun 2015 (A/70/95-S/2015/446).

Kedua, laporan Kelompok Penasehat Pakar mengenai tinjauan arsitektur peacebuilding Perserikatan Bangsa-Bangsa (A/69/968-S/2015/490).

Ketiga, Agenda 2030 untuk Pembangunan Berkelanjutan dan agenda perempuan, perdamaian dan keamanan.

Jika semua itu diperhatikan, maka semestinya apa yang dimaksud membangun komitmen kolektif untuk tujuan-tujuan melakukan pencegahan haruslah diletakkan 
pada prioritas yang tak boleh ditawar. Hanya dengan begitulah pencegahan penyebaran violent extremism menjadi semakin relevan.

Boleh jadi dapat diidentifikasi sebagai sebuah progress yang penting dicatat, bahwa Strategi Penanggulangan Terorisme Clobal PBB telah diadopsi dengan suara bulat oleh Majelis Umum PBB dengan resolusi 60/288.

Dokumen kesepakatan ini secara eksplisit membahas pencegahan dan perkiraan implementasi yang seimbang pada keempat pilarnya, yakni: pertama, menanggulangi kondisi yang kondusif bagi terorisme; kedua, mencegah dan memberantas terorisme; ketiga, membangun kapasitas negara untuk memerangi terorisme dan memperkuat peran sistem PBB di dalamnya; dan keempat, memastikan penghormatan terhadap hak asasi manusia untuk semua dan peraturan hukum saat melawan terorisme.

Tetapi PBB mencatat bahwa selama dekade terakhir, justru yang mendapat penekanan kuat dari keempat pilar itu hanyalah pada penerapan tindakan di bawah pilar kedua, sedangkan pilar pertama dan keempat terlalu sering diabaikan. Padahal menanggulangi kondisi yang kondusif bagi terorisme dan memastikan penghormatan terhadap hak asasi manusia untuk semua dan peraturan hukum saat melawan terorisme mestinya dapat mereduksi keseuruhan masalah jika diprioritaskan secara sungguh-sungguh.

Di berbagai Negara seperti Indonesia, menjelang ulang tahun kesepuluh penerapan Strategi tersebut, pada tahun 2016, kenyataan tetap belum banyak berubah. Rakyat dibiarkan tidak perlu tahu apa agenda Negara, malah sebaliknya memilih memaksa rakyat wajib percaya atas semua tindakan Negara jika pun itu sesuatu hal yang sangat tidak masuk akal.

\section{Bagian V}

Di tengah persiapan memasuki bulan suci Ramadhan $1394 \mathrm{H}$ kerusuhan terjadi Mako Brimob yang membawa korban manusia dari pihak aparat (Kepolisian) maupun perusuh (napiter). Kemudian terjadi rangkaian teror di berbagai tempat di Indonesia.

Kasad Jenderal Mulyono saat memberikan arahan di hadapan prajurit Batalyon Infanteri (Yonif) 133/Yudha Sakti, Jumat (18/5) menaruh kecurigaan atas adanya pihak asing yang 'bermain' dalam aksi-aksi bom bunuh diri tersebut ${ }^{52}$.

"Bangsa lain sangat iri dengan kekayaan alam dan budaya yang dimiliki Indonesia. Selain keberagaman budaya, mereka juga ingin mendapatkan kekayaan alam Indonesia ini, namun sering dilakukan dengan cara tidak sehat, salah satunya adalah dengan aksi teror bom yang belakangan terus menghantui masyarakat Indonesia" 53 . 
la melihat, aksi teror bom adalah salah satu cara negara lain untuk memperebutkan kekayaan alam Indonesia selain dengan peredaran narkoba. Namun Mulyono tak menyebut negara mana berada di belakang aksi teror yang diduga akan memecah belah persatuan Indonesia.

\footnotetext{
"Saat ini, kita harus bersatu agar tidak mudah dipecah belah oleh negara lain. Aparat keamanan dan pertahanan harus bersatu, jika ada masalah antar-instansi selesaikan dengan baik-baik. Karena hanya dengan demikian, negara lain tidak akan bisa memecah belah bangsa ini. Jika terpecah, negara lain akan datang dengan dalih melakukan aksi perdamaian".
}

Sejalan dengan itu Prof. Dr H Din Syamsuddin menegaskan bahwa terorisme bukan hanya faktor ideologi (radikal) saja tetapi juga bisa menjadi sangat subur karena faktor-faktor rumit yang berkelindan dalam Poleksosbud. Indonesia yang selama ini memilih hanya percaya dan merasa hanya benar untuk fokus memerangi ideologi saja dan mengabaikan masalah politik, ekonomi, keadilan sosial dan budaya lokal atau politik global, ternyata tak mampu menyintuh akar masalah yang tidak ditemukan sama sekali. Semua kerumitan ini bersifat global, dan jangan nafikan bahwa ini berkaitan dengan operasi intelijen. Intelijen itu bisa asing dan bisa juga lokal.

Para pelaku teror akhirnya menjadi jelas hanya sebagai pion belaka. Ada yang memeliharanya. Mereka diciptakan, untuk pada suatu ketika yang dianggap tepat untuk diperangi sendiri sesuai kepentingan pememeliharaan kepentingan. Auditlah kerugian kemanusiaan dengan perspektif itu. Tentu Anda akan berkata betapa siasianya lilin-lilin yang dibakar oleh mobilisasi-mobilisasi sistematis yang pesan akhirnya pun menyisakan kekeruhan. Ucapan-ucapan gagap yang diviralkan pun, seperti "kami tak takut teror", "Kami mendukung Kepolisian”, akhirnya terasa menjadi upaya menyembunyikan akar masalah sesungguhnya ${ }^{54}$.

Rizal Ramli ${ }^{55}$ dalam dialog dengan sebuah televisi swasta bersama Salim Said dengan tema "Ekonomi Dalam Bingkai Pancasila" begitu tegas mengatakan bahwa radikalisme atau semacamnya tidak perlu dikhawatirkan di sebuah negara yang rakyatnya sejahtera. Inilah agenda yang ditelantarkan dari satu ke lain rezim, dengan catatan kegagapan dalam memilih strategi dan model pembangunan yang terlalu kanan (neoliberalis).

Kita semua ingat bahwa pasca rangkaian kejadian teror belakangan ini langsung saja masalah Revisi Undang-Undang nomor 15 tahun 2003 tentang Pemberantasan Tindak Pidana Terorisme menjadi sorotan. Pembahasannya yang cukup lama tertunda menjadi pusat perhatian penting. Presiden Joko Widodo sendiri pun berkata: "Saya juga minta ke DPR dan kementerian terkait yang berhubungan dengan revisi UU Tindak Pidana Terorisme, yang sudah kita ajukan pada bulan Februari 2016 yang lalu, sudah dua tahun, untuk segera diselesaikan secepat-cepatnya dalam masa sidang berikut 18 Mei yang akan datang" 56 . Joko Widodo menyatakan itu melalui akun Twitter-nya. 
Tetapi Wakil Ketua MPR Hidayat Nur Wahid tak mau menerima tudingan itu. Malah ia meminta agar Presiden menegur saja dulu Menkumham, Yasonna H Laoly. Penyebab keterlambatan ada di sana. Wakil pemerintah dalam pembahasan RUU Teror (Yasonna $\mathrm{H}$ Laoly) itulah yang telah berulah, dan telah menyebabkan keterlambatan penyelesaian RUU Teror. Yasonna $\mathrm{H}$ Laoly sudah beberapa kali berusaha menunda pembahasan RUU Teror. Ada surat resminya. Tak hanya Hidayat Nur Wahid yang menyatakan kegusaran. Bahkan Ketua DPR RI Bambang Soesatyo, dan Ketua Pansus RUU Teror Romo Raden M. Syafi'i, juga angkat bicara, protes, bahwa masalah keterlambatan pembahasan RUU Teror justru ada pada pihak pemerintah.

Terasalah "ultimatum" Presiden Joko Widodo dengan nada mengancam akan mengeluarkan Peraturan Pemerintah Pengganti Undang-Undang (Perppu) itu menjadi aneh. Mengapa Menkuham Yasonna $\mathrm{H}$ Laoly menunda-nunda? Apa masalah sesungguhnya?

Diskursus tentang UU terorisme di Indonesia selama ini diwarnai oleh beberapa hal terpenting apa terorisme itu, apa akar masalahnya, bagaimana menghadapinya dan bagaimana tentang pembinaan lanjut. Peneliti Wahid Foundation, Rumadi Ahmad, misalnya, melihat revisi UU 15/2003 terlalu berlebihan dan malah lebih mengisyaratkan negara yang ketakutan terhadap terorisme. Padahal semua tahu bahwa dengan UU yang ada Densus 88 Polri telah menjalankan tugasnya.

Desakan dari berbagai pihak sesungguhnya bukan tak diindahkan oleh Pansus RUU Teror. Ketua Pansus Romo H Raden M. Syafii menyatakan bahwa keterlambatan pembahasan merupakan keniscayaan karena pentingnya menyelenggarakan rangkaian Rapat Dengar Pendapat Umum (RDPU) dengan berbagai pihak untuk memeroleh masukan. Draf RUU Teror yang diusulkan pemerintah itu memang, singkatnya, tidak dapat ditelan bulat-bulat untuk disetujui. Banyak hal yang dipandang krusial.

Sebagaimana luas diketahui, RUU Teror versi pemerintah mereferensi Internal Security Act (ISA) Singapura dan Malaysia. Misalnya, pasal 73 ayat 1 ISA Malaysia ditegaskan bahwa polisi bisa menahan seseorang selama 60 (enam puluh hari) hari tanpa surat perintah dan bantuan hukum. Setelah itu Kementerian Dalam Negeri Malaysia bisa memperpanjang masa tahanan tanpa sidang sampai dengan dua tahun. Itu semua bisa dilakukan tanpa menyertakan bukti apa pun. Kalangan civil society di Indonesia pastilah sangat menolak ketentuan ini karena dipandang sangat riskan (kesewenangwenangan penguasa).

Institute for Criminal Justice Reform (ICJR) berpendapat jangankan 60 hari, bahkan waktu 30 hari pun sudah terlalu lama. ICJR membedakan antara penangkapan dan penahanan. Esensi keduanya sangat berbeda terutama jika merujuk pada pasal 1 angka 20 KUHAP (penangkapan adalah suatu tindakan penyidik berupa pengekangan sementara waktu kebebasan tersangka atau terdakwa). Meski pun waktu untuk proses

11 Mengapa Teror Harus Abadi? 
mengejar dan menangkap itu tidak dibatasi oleh hukum acara, namun setelah seseorang atau sekelompok orang menjadi tersangka, masa penangkapan otomatis wajib dihitung untuk kemudian dilanjutkan dengan proses berikutnya.

Kiranya dapatlah difahami kekhawatiran ICJR bahwa penangkapan dalam jangka waktu lama selalu bisa berakibat fatal. Terbuka peluang besar pelanggaran HAM (apalagi dalam kasus terorisme). Memang jika suara orang-orang tertentu yang muncul pada media sosial disimak, bahkan pelaku teror itu bagi mereka terlalu beroleh kemewahan jika diberi HAM. Namun masalahnya apakah setiap orang yang dicurigai sebagai pelaku teror sudah benar-benar akan terbukti sebagai orang yang bertanggungjawab atas sebuah tindakan jahat yang dituduhkan? Ingatlah kasus Siyono.

Lagi pula, penahanan bersifat incommunicado (tanpa akses terhadap dunia luar) selalu membuka peluang besar untuk praktik yang bertentangan dengan HAM. Pelaksanaan penindakan (atas tindak pidana teror) dengan model ISA Singapura dan Malaysia itu tidak ideal dan tidak sesuai dengan nurani hukum dan keadilan di Indonesia. Jika akan diterapkan, tegas anggota DPR Nasir Djamil, diyakini berpotensi keluar dari jalur hukum, amat rawan digunakan oleh rezim untuk melakukan kesewenang-wenangan. Dengan amat tak suka ia membandingkan perlakuan Duterte dari Filipina. Apa pun alasan (bagi pemerintah) untuk mengadopsi ISA model Singapura dan Malaysia, banyak pihak serius menolaknya.

Selain itu masalah lain yang juga dipandang krusial ialah pelibatan TNI. Diketahui, sebetulnya sudah terdapat aturan landasannya pada UU TNI Pasal 7 ayat (2) tentang Operasi Militer Selain Perang (OMSP). Jika demikian hanya diperlukan sebuah mekanisme yang jelas dan terukur (akuntable) untuk menghindari penyalahgunaan wewenang.

Mengapa pelibatan TNI menuai kritik? Ada yang berpendapat (Koalisi Masyarakat Sipil untuk Reformasi Sektor Keamanan) bahwa pelibatan militer tidak perlu dalam revisi UU Teror. Kalangan ini berdalih bahwa UU yang diharapkan ialah UU yang dapat mengatur sebaik-baiknya dan secara terukur tata cara penegakan hukum. Hal yang perlu diatur adalah institusi-institusi terkait dengan penegakan hukum, bukan yang lain. Kalangan ini juga berpendapat bahwa TNI, berdasarkan UU Nomor 34 tahun 2004, tidak memiliki tugas utama sebagai penegak hukum, melainkan menjaga kedaulatan negara. UU telah mengatur keterlibatan TNI dalam tugas selain perang atas keputusan politik negara.

Meski pun akhirnya kini sudah seakan difahami bersama, bahwa mekanisme pelibatan TNI memang perlu diatur meski landasannya sudah ada pada UU yang lain, namun Haris Azhar yang mantan Koordinator KontraS juga pernah mengeritik tak kurang kerasnya. Baginya masalah utama dari penanggulangan terorisme khususnya di 
Indonesia adalah pada sisi akuntabilitas, bukan seberapa penting melibatkan atau tidak melibatkan TNI.

\section{Bagian VI}

Seorang analis militer berpendidikan Barat dari Indonesia (Salim Said), baru-baru ini telah berbicara cukup menohok pada sebuah stasiun televise Swasta Nasional sekaitan dengan kegandrungan melabeli setiap tindakan kekerasan sebagai pekerjaan ISIS. Selain mengkonfirmasi kaitan sejarah kepenjajahan negeri ini yang sesungguhnya adalah menjadi beban terberat sepihak bagi mereka yang beragama Islam, Salim Said memiliki kesamaan pandangan dengan Daniel S Lev 57 .

Dominasi, terutama dalam bidang ekonomi, yang diikuti oleh dominasi politik dan budaya, lambat laun melahirkan rasa ketidak-adilan dan bahkan rasa keterampasan (relative deprivation). Mungkin ada orang atau golongan yang sangat mahir dan sudah sangat terlatih bersandiwara untuk memenangkan persaingan atas nama agama yang disamarkan sedemikian rupa, sedangkan yang lain tak terlatih untuk itu dan dengan demikian selalu akan menjadi korban yang potensil dikukuhkan dalam logika generalisasi yang sangat simplistis.

Daniel S Lev sudah barang tentu benar untuk satu hal, tetapi tidak untuk yang lain. la tak berdiri pada posisi yang dapat melihat semua variable yang menyebabkan kerumitan yang luar biasa ini. Karena itu, menuntut berbagai instrumen yang berkeinginan semakin mengokohkan pentingnya perumusan baru mengenai peran agama atau kerukunan beragama dalam pertumbuhan negara-bangsa untuk tujuan menekan sepihak, sangatlah tidak bijak.

Orang selalu memilih untuk tak mampu dengan jujur melukiskan duka dalam peradaban terjajah secara ekonomi, politik dan budaya. Padahal dunia internasional semestinya kini sudah mulai melakukan pertaubatan serius atas paradigma yang digunakan selama ini dalam memandang terorisme. Dangkal sekali, memang.

Belajar dari kasus-kasus yang sudah terjadi dalam kategori terorisme di Indonesia selama ini, agaknya Negara harus menyadari apa yang sedang menimpanya. Negara pun tak boleh menjadi mainan bagi instrumen global yang tak menjamin keadilan yang hakiki. Para pemimpin umat Islam di Indonesia seharusnya menyadari kerugian besar memilih membangun arena besar saling tuding sembari secara tersamar saling memasang kuda-kuda untuk beroleh reward dari tukang ponten, atau pihak yang kurang lebih secara serampangan dan secara pragmatis dianggap patut dipertuan.

Ngomong-ngomong, Anda mau heran gak ya ketika di Indonesia disebut-sebut begitu meluasnya ISIS, namun pada saat yang sangat favourable seperti gelombang aksi terbesar (aksi superdamai 212) sebuah gelas pun tak pecah di arena? Atau ketika 
sebuah aksi terror di lumpuhkan di sekitar Sarinah (Jakarta), Presiden RI Joko Widodo datang ke lokasi beberapa jam kemudian hanya dikelilingi oleh pengawal tanpa perangkat pengaman standard (padahal untuk meninjau proyek saja lazim Presiden Jokowi memakai baju rompi dan topi pengaman).

Jika dunia internasional mengaitkan ISIS sebagai ekspresi totalistas Islam yang brutal, maukah Anda ikut heran bersama saya ketika penistaan yang direstui dunia terjadi begitu dahsyat di Palestina dan ISIS itu tak tersinggung?

${ }^{1}$ Lihat Sebastian Wojciechowski dari Adam Mickiewicz University: Why is it so Difficult to Define Terrorism? (2009). Tetapi secara tidak adil penulis ini menimpakan secara berimbang dampak 911 bahwa: (1) Baik Jihadis Islam dan dua pemerintahan Bush telah menyebarkan kacamata teror untuk mempromosikan agenda politik mereka; bahwa keduanya menyebarkan wacana Manichean tentang kebaikan dan kejahatan yang dengan sendirinya sesuai dengan kode media yang dominan dari budaya populer; dan keduanya menyebarkan diskursus fundamentalis dan absolut. (2) Baik terorisme Islam dan militerisme AS, dan menyerukan tanggapan multilateral dan global terhadap terorisme dan rezim jahat. Saya juga berpendapat bahwa Internet adalah sumber informasi terbaik mengenai peristiwa-peristiwa kompleks seperti Teror Perang, sementara media korporasi AS utama, terutama penyiaran, telah menjadi alat propaganda untuk pemerintahan Bush dan Pentagon selama kacamata terorisme dan perang. (3) Keterbatasan terhadap politik tontonan dan berpendapat bahwa catatan dari kacamata Perang Teror dalam beberapa tahun terakhir menyingkap efek politik yang sangat ambigu, tidak dapat diprediksi, dan negatif.

${ }^{2}$ Lihat Douglas Kellner: 9/11, spectacles of terror, and media manipulation, A critique of Jihadist and Bush media politics, Pages 41-64 | Published online: 15 Aug 2006. War on terrorism tercatat kian gencar pasca serangan 911 dan sasarannya lebih kepada dunia Islam. Padahal dari 38 video beredar tentang kejadian ini terbukti bahwa kebohongan (hoax) telah dipakai sebagai senjata. Tak mungkin pesawat terbang dengan bahan utama aluminium bisa menembus konstruksi baja gedung WTC. Tidak mungkin ketinggian gedung yang mesti dilewati sebelum menabrak WTC dapat memperkenankan sebuah pesawat terbang menembus WTC sebelum merobohkan gedung yang menghadang pada jarak yang lebih dekat. Tetapi ini sudah menjadi opini dunia dan setiap hari memperburuk citra dan posisi Islam dalam pergaulan internasional.

${ }^{3}$ Haroon Moghul (2017): I know there's a double standard when it comes to Muslims and violence, but these last few instances have been peculiarly egregious. If it's true that all terrorists are Muslims, it's just because we've defined terrorism so that it's pretty much only restricted to violence committed by Muslims.

${ }^{4}$ Setiap agama dan kelompok budaya memiliki dimensi doktrinal atau mitos yang bertalian dengan teror. la bisa bekerja internal mau pun eksternal, sesuai dengan kompleksitas masalah yang terjadi.

${ }^{5}$ James C. Scott, Weapons of the Weak, Everyday Forms of Peasant Resistance, 1987.

${ }^{6}$ Si Pitung, Si Jiih, Naga Bonar, Tjut Njak Dhien, bahkan Sisingamangaraja adalah beberapa contoh tipikal perlawanan rakyat atas kolonial Belanda yang oleh penjajah selalu dikategorikan teror. Untuk kasus Sisingamangaraja Periksa Uli Kozok, Utusan Damai Di Kelemut Perang, Yayasan Obor Indonesia (YOI), 2010.

${ }^{7}$ Rizal Ramli (2017) menegaskan tidak ada kekhawatiran munculnya kelompok ektrimis, radikalis dan separatis di negara yang rakyatnya makmur dan dengan pemerintahan yang adil dan melindungi. Sayangnya membaca ketidakadilan itulah yang selalu tak dilakukan oleh setiap rezim.

${ }^{8}$ RAND Corporation. (2013): Paths to Victory.

${ }^{9}$ Lihat: http://www.pewforum.org/2001/10/05/just-war-tradition-and-the-new-war-on-terrorism/

${ }^{10}$ Czar Alexander II, the ruler of Russia since 1855, is killed in the streets of St. Petersburg by a bomb thrown by a member of the revolutionary "People's Will" group. The People's Will, organized in 1879, 
employed terrorism and assassination in their attempt to overthrow Russia's czarist autocracy. They murdered officials and made several attempts on the czar's life before finally assassinating him on March 13, 1881. Lihat: https://www.history.com/this-day-in-history/czar-alexander-ii-assassinated

11 Approximately three thousand workers turned out for the Haymarket protest. The mayor of Chicago, Carter Harrison (1825-1893), attended the meeting and informed police officials that the audience and the speakers were peaceful. The mayor and most of the workers left by 10:20 p.m., when a light rain set in. Only 500 workers remained when 180 Chicago policemen arrived to disband the meeting. A police official who had been in political conflict with the mayor ordered the immediate evacuation of the public square. Lihat: https://www.encyclopedia.com/history/united-states-and-canada/us-history/haymarket-square-riot.

12 He had been shot on September 6, 1901, by anarchist Leon Czolgosz (pronounced chol-gosh) at the Pan-American Exposition in Buffalo, New York. The president died on September 14. Lihat: https://archive.nytimes.com/www.nytimes.com/learning/general/onthisday/harp/0914.html.

${ }^{13}$ The turn of the century was a brutal time in the fight to organize labor. San Francisco was by then heavily unionized, but the battle for Los Angeles was heated and ongoing. There were rowdy rallies and workers clashed violently with police. A few months before the bombing, the Iron Workers Union went on strike, which resulted in the city creating an anti-picketing ordinance. Workers with union ties were not hired and replaced with non-union workers. Businesses that did this were frequently bombed. The failure to unionize Los Angeles was often attributed to one man: Los Angeles Times owner Harrison Gray Otis, who used the paper to trumpet his anti-union views. Otis, a Civil War captain, was hellbent on ridding the city of unions, and was known to pay strikebreakers. He drove around town with a cannon mounted on the hood of his limousine. Labor supporters considered him, "depraved, corrupt, crooked, and putrescent." Lihat: https://timeline.com/los-angeles-times-bombing-c2fbf1e02fab.

${ }^{14}$ First World War centenary: the assassination of Franz Ferdinand, as it happened. On Sunday June 281914 in Sarajevo, Gavrilo Princip fired the shot that killed the Archduke and started the train of events that led to global war. Here is a step by step account of how the dramatic day unfolded. Lihat: https://www.telegraph.co.uk/history/world-war-one/10930863/First-World-War-centenary-the-assassinationof-Franz-Ferdinand-as-it-happened.html.

${ }^{15}$ It is exactly 90 years on April 16, since the bomb attack on the St. Nedelya church in Sofia. This is one of the bloodiest political terrorist attacks in world history. The events in April 1925 are a tragic stage in the political crisis in Bulgaria in the wake of the country's defeat in World War I. In June 1923, after a series of errors, the left-wing government of the Agrarian Union was overthrown in a military coup and the attempted rebellion against the new right-wing government that ensued was crushed. The communist party got involved in the events late after pressure from the Communist International which made an erroneous evaluation of the situation in Bulgaria. So it came about that the September uprising the communist party headed was routed. Yet it continued its political line towards an armed struggle. In May 1924, a conference took place on Mount Vitosha at which an underground military organization was set up, headed by Major Kosta Yankov. Lihat: http://bnr.bg/en/post/100546082/ninety-years-since-the-bomb-attack-on-st-nedelya-church.

${ }^{16}$ The assassin Vlada Georgieff - driver of the leader of the Internal Macedonian Revolutionary Organization, Ivan Mihailov - was cut down by the sword of a mounted French policeman, then beaten by the crowd. By the time he was removed from the scene, he was already dead. King Alexander I was buried in the Memorial Church of St. George, built by King Peter I. As his son Peter II was still a minor, Alexander's cousin Pavle Karadjordjevic took the regency of the Kingdom of Yugoslavia. Lihat: http://www.1066.co.nz/Mosaic\%20DVD/whoswho/text/Alexander I of Yugoslavia[1].htm

17 Ophélie Eguienta: Twenty-First Century Police Brutality against African Americans: The Case of Ferguson, Missouri, and the "Black Lives Matter" Movement, Université Toulouse II Jean Jaurès, 2017.

${ }^{18}$ Ophélie Eguienta: ibid.

${ }^{19}$ Ophélie Eguienta: ibid. 
${ }^{20}$ Ophélie Eguienta: ibid.

${ }^{21}$ Lihat: https://www.history.com/topics/oklahoma-city-bombing

${ }^{22}$ Lihat: https://en.wikipedia.org/wiki/History_of_the_Israeli\%E2\%80\%93Palestinian_conflict.

${ }^{23}$ Lihat: http://www.informationclearinghouse.info/article4667.htm.

${ }^{24}$ Lihat: https://en.wikipedia.org/wiki/Red_Army_Faction.

${ }^{25}$ Lihat: https://en.wikipedia.org/wiki/Kidnapping_of_Aldo_Moro.

${ }^{26}$ Lihat: https://is.muni.cz/el/1423/podzim2016/BSS411/um/carus.txt.

${ }^{27}$ Lihat: http://www.bbc.co.uk/history/topics/troubles_violence.

${ }^{28}$ Lihat: https://www.knmc.lt/alvoie/xlbeir.php?vm=eta-attacks.

${ }^{29}$ Lihat: http://althistory.wikia.com/wiki/Lord\%27s_Resistance_Army_(Kony_Captured)

${ }^{30}$ Lihat: https://fas.org/irp/world/para/docs/com77e.htm.

${ }^{31}$ RAND Corporation. (2013): Paths to Victory.

${ }^{32}$ Terrorism Research Initiative: Perspectives on terrorism Volume VI, Issue 2 May 2012.

${ }^{33}$ Lihat: https://www.haaretz.com/jewish/holocaust-remembrance-day/.premium-6-million-where-isthe-figure-from-1.5319546.

${ }^{34}$ Lihat: https://en.wikipedia.org/wiki/Politburo_of_the_Communist_Party_of_the_Soviet_Union.

${ }^{35}$ Lihat: https://www.quora.com/How-did-Mao-manage-to-kill-78-million-people.

${ }^{36}$ Lihat: https://hisamullahbeg.blogspot.com/2015/02/in-history-of-world-who-has-killed.html.

${ }^{37}$ Lihat: https://www.history.com/this-day-in-history/robespierre-overthrown-in-france.

${ }^{38}$ Lihat: https://en.wikipedia.org/wiki/Kalinga_War.

${ }^{39}$ Lihat:https://www.nytimes.com/2003/01/26/weekinreview/the-world-how-many-people-hashussein-killed.html.

40 Lihat: https://www.independent.co.uk/news/world/asia/suharto-one-of-the-greatest-massmurderers-of-the-20th-century-777103.html dunia.html.

${ }^{41}$ Lihat: https://www.merdeka.com/pendidikan/gold-gospel-dan-glory-3g-dalam-sejarah-ekspedisi-

${ }^{42}$ Lihat: https://www.britannica.com/event/Thirty-Years-War.

${ }^{43}$ Lihat: https://www.museeprotestant.org/en/notice/the-eight-wars-of-religion-1562-1598/

${ }^{44}$ Lihat: https://id.wikipedia.org/wiki/Perang_Salib.

${ }^{45}$ Lihat: https://www.jww.org/conflict-areas/sudan/north-south-conflict/. 
${ }^{46}$ Lihat: https://www.globalsecurity.org/military/world/war/lebanon.htm

${ }^{47}$ Lihat:https://www.cnnindonesia.com/internasional/20170926124021-106-244093/pengadilaninternasional-vonis-myanmar-lakukan-genosida.

${ }^{48}$ Lihat antara lain: https://id.wikipedia.org/wiki/Terorisme di Indonesia. https://www.tempo.co/tag/bom-di-indonesia. https://tirto.id/empat-generasi-dalam-sejarah-terorisme-cwpb.

49 Di sini ada catatan penting yang harus diberikan, bahwa violent extremism itu kelihatannya dianggap mencakup kategori manifestasi yang lebih luas dan ada risiko bahwa pembenaran penerapan tindakan kontra-terorisme yang terlalu luas itu telah dijadikan tameng untuk menyembunyikan sebuah agenda jahat untuk tujuan menyudutkan Islam. Ini dapat dilihat secara jelas dari tingkah-tingkah Negara-negara dan aparat yang mereka persiapkan untuk menghadapi apa yang disebut sebagai bahaya teror, meski selalu mendapat kecaman. Tetapi sebagian besar mereka tidak bersedia merevisi tindakan, apalagi cara pandang.

${ }^{50}$ Ada norma internasional yang sengaja diabaikan, dan lembaga internasional kelihatannya memilih lebih baik menonton saja atas penyimpangan-penyimpangan serius itu. Inilah yang diabaikan begitu saja sambil berusaha beretorika, menyembunyikan niat jahat yang sebetulnya sangat diinginkan.

51 PBB pun kelihatannya membiarkan diri sebagai institusi kebodohan besar yang sangat kejam. Bahwa untuk diketahui, hingga kini, untuk perumusan definisi terorisme dan violent extremism itu saja adalah sesuatu yang dianggap sebagai hak prerogatif Negara-negara anggota. Betapa pun itu bisa saja sangat bertentangan dengan semangat dan standar humanisme internasional. Meski PBB tak lupa menegaskan keniscayaan adanya konsistensi dengan kewajiban menerapkan seluruh tindakan yang berdasarkan hukum internasional, khususnya hukum hak asasi manusia internasional, tetapi semua itu sangat terasa sebagai retorika double talk (munafik) belaka.

52 Tak sampai sepekan pasca bom Surabaya, pimpinan Nahdhatul Ulama sudah bertandang kepada Wakil Presiden Amerika Serikat. Mereka berbicara untuk mempromosikan kebebasan beragama dan memerangi ekstremisme. Moore, seorang juru bicara de-facto untuk kelompok pemimpin evangelikal konservatif yang secara informal menyarankan administrasi Trump, mengatakan bahwa pertemuan itu terjadi ketika Yahya berada di AS dalam perjalanan yang direncanakan sebelumnya untuk sejumlah pertemuan di seluruh negeri. Setelah pertemuan itu, Pence mengirim tweet sebuah foto dengan Yahya dan memujinya atas upaya organisasinya. Lihat: http://www.nu.or.id/post/read/90768/nu-leader-meets-us-vice-president-daysafter-surabaya-bombings.

53 Lihat: https://www.merdeka.com/peristiwa/kasad-curiga-teror-bom-di-tanah-air-ada-campurtangan-pihak-asing.html.

54 Prof Dr H Dien Syamsuddin juga mengingatkan pemerintah agar tidak terlalu berambisi membuat regulasi yang kurang mempertimbangkan keserasian dengan konstitusi. Pengalaman berkali-kali dikalahkan oleh gugatan rakyat pada sidang judicial review pada Mahkamah Konstitusi benar-benar menunjukkan ketakmatangan cara berfikir pemerintah. Betapa tidak, kini kita hidup pada alam demokrasi. Dunia pun juga memerhatikan kita. Regulasi seperti Perppu, yang dibuat terburu-buru, lazimnya akan menonjol emosionalitasnya dan akhirnya ketak-sempurnaannya sekaligus. Itu sangat terbuka untuk segera dibatalkan oleh Mahkamah Konstitusi, atas gugatan rakyat. Pemerintah juga perlu memupuk harga diri agar berwibawa. Tidak asal-asalan. Juga tidak mengesankan pentingnya kekuasaan eksekutif (diktatorship) di atas segalanya.

${ }^{55}$ Rizal Ramli (2017), ibid.

${ }^{56}$ Lihat: $\underline{\text { https://twitter.com/jokowi/status/995876864164966400. }}$.

${ }^{57}$ Bagi Daniel S. Lev salah satu persoalan yang cukup pelik di Indonesia saat ini adalah bagaimana mengatasi ketegangan dalam hubungan antara negara dengan agama yang, faktanya, hal ini sekaligus terkonfirmasi secara meyakinkan tentang semakin menguatnya dominasi ekonomi, sosial dan politik yang 
melahirkan berbagai bentuk ketegangan kontestasi dan konflik yang tak seorang pun mampu mereduksi agar tak ditemalikan dengan agama tertentu. 